\title{
A new platinum(II) compound anticancer drug candidate with selective cytotoxicity for breast cancer cells
}

\author{
This article has been corrected since Online Publication and a corrigendum has also been published
}

\author{
A Muscella ${ }^{*, 1,3}$, C Vetrugno ${ }^{1,3}$, FP Fanizzi ${ }^{1}$, C Manca ${ }^{2}$, SA De Pascali ${ }^{1}$ and S Marsigliante ${ }^{1}$
}

[Pt(0,0'-acac)( $\gamma$-acac)(DMS)] (PtAcD) is able to induce apoptosis in various human cancer cells, including the cisplatinresistant human breast carcinoma MCF-7 cells. Here, to confirm that PtAcD has the potentiality for therapeutic intervention, we studied its effects in primary cultured epithelial breast cells obtained from cancers and also from the corresponding histologically proven non-malignant tissue adjacent to the tumor. We demonstrated that PtAcD (1) is more cytotoxic in cancer than in normal breast cells; (2) activated NAD(P)H oxidase, leading to PKC- $\zeta$ and PKC- $\alpha$ tanslocations; (3) activated antiapoptotic pathways based on the PKC- $\alpha$, ERK1/2 and Akt kinases; (4) activated PKC- $\zeta$ and, only in cancer cell PKC- $\delta$, responsible for the sustained phosphorylation of p38 and JNK1/2, kinases both of which are involved in the mitochondrial apoptotic process. Moreover, crosstalk between ERK/Akt and JNK/p38 pathways affected cell death and survival in PtACDtreated breast cell. In conclusion, this study adds and extends data that highlight the pharmacological potential of PtAcD as an anti breast cancer drug.

Cell Death and Disease (2013) 4, e796; doi:10.1038/cddis.2013.315; published online 12 September 2013

Subject Category: Cancer

Although many cancers initially respond to chemotherapy, subsequent resistance in responsive tumors is a major clinical problem and a cause for failure in the curative therapy. Modification of platinum-based compounds is a promising approach for the development of non-cross-resistant analogs of cisplatin (cisPt), and a large number of mononuclear Pt compounds have been developed as potential candidates for clinical use. ${ }^{1}$

In this context, new $\mathrm{Pt}$ (II) complexes have been specifically synthesized by some of us in order to overcome the cisplatinrelated problems. ${ }^{2,3}$ The ability of these new $\mathrm{Pt}$ (II) compounds to induce apoptosis in human cancer cells has been studied and compared with the well-established anticancer drug, cisPt, among them, $\left[\mathrm{Pt}\left(\mathrm{O}, \mathrm{O}^{\prime}\right.\right.$-acac $)(\gamma$-acac $\left.)(\mathrm{DMS})\right](P t A c D)$ exhibited the highest in vitro activity. In addition, the reactivity of these novel complexes with nucleobases and sulfur ligands suggests that their cytotoxicity may not necessarily require reaction with DNA. ${ }^{3} P t A c D$ reaches the central nervous system in doses much higher than cisPt. Nevertheless, $P t A c D$ displayed a low neurotoxicity in normal tissues. ${ }^{4}$ We also showed that PtAcD exhibited higher antitumor activity than cisPt on MCF-7 and in other breast cancer cell lines, but not in MCF-10A cell lines, which are considered to be normal and non-cancerous breast cells. ${ }^{5}$ These data deserve further investigation, as it is important to determine whether PtAcD is specifically toxic for cancer cells. To this end, we made primary epithelial cell cultures from 30 breast cancers that may retain specific physiological function of origin mammalian tissue. ${ }^{6}$ The effects of $P t A c D$ were studied in primary cultured tumoral cells and also in cells obtained from the corresponding histologically proven nonmalignant tissue adjacent to the tumor, in order to evaluate the responsiveness of the two cell types obtained from the same patient. Modulation of mitogenactivated protein kinases (MAPKs) signaling has been shown in many cases to influence the apoptotic response to antitumor agents. ${ }^{7}$ The MAPK cascades have a complex and controversial role in determining the ultimate fate of the cells depending on the cell type and molecular background. In this study, we also investigated the effects of PtAcD on MAPKs and some other important intracellular transduction pathways involved in the processes of apoptosis and/or cell survival. We established a link between the activation of these pathways and the different cytotoxicity exerted by $P t A c D$ in healthy and cancerous cells.

\section{Results}

Cytotoxicity of the drugs. Cells were treated with various concentrations of PtAcD or cisPt, and viable cell number was determined by 3-(4,5-dimethylthiazol-2-yl)-2,5-diphenol tetrazolium bromide (MTT) metabolic assay and confirmed

\footnotetext{
'Di.S.Te.B.A., University of Salento, Lecce, Italy and ²Division of General Surgery, A.O. "Vito Fazzi", Lecce, Italy

*Corresponding author: A Muscella, Laboratorio di Patologia Cellulare, Dipartimento di Scienze e Tecnologie Biologiche e Ambientali (Di.S.Te.B.A.), Università del Salento, Via Provinciale per Monteroni, Lecce 73100, Italy. Tel: + 390832 298617; Fax: + 390832 298626; E-mail: antonella.muscella@unisalento.it

${ }^{3}$ These two authors contributed equally to this work.

Keywords: tumor breast cells; p38; JNK; ERK; Pt(II) complexes

Abbreviations: PtAcD, [Pt $\left(0, \mathrm{O}^{\prime}\right.$-acac) $(\gamma$-acac)(DMS)]; cisPt, cisplatin; EGFR, epidermal growth factor receptor; ER, estrogen receptors; ERK1/2, extracellular regulated kinase 1/2; JNK, c-Jun N-terminal kinases; MEK, MAPK/ERK kinase; MTT, 3-(4,5-dimethylthiazol-2-yl)-2,5-diphenol tetrazolium bromide; NBT, nitroblue tetrazolium; PgR, progesterone receptor; PI3K, phosphatidylinositol 3-kinase; PKC, protein kinase c; siRNAs, small interfering RNAs; SRB, sulforhodamine B

Received 23.5.13; revised 27.6.13; accepted 01.7.13; Edited by M Agostini
} 
by sulforhodamine B (SRB) assay 12, 24, 48 and $72 \mathrm{~h}$ later. Comparable results were obtained when the cell number was directly determined by cell counting; therefore, we used the MTT assay in the experiments described hereafter. Both PtAcD and cisPt provoked a dose-dependent decrease in cell survival, at different extent. In breast cancer cells, PtAcD cytotoxicity was approximately 16-fold greater than that observed for cisPt $\left(\mathrm{IC}_{50} 5.3 \pm 0.4 \mu \mathrm{M}\right.$ for PtAcD and $\mathrm{IC}_{50} 94.7 \pm 3.4 \mu \mathrm{M}$ for cisPt, $P<0.0001$, after $72 \mathrm{~h}$ treatment, $n=30$ primary cultures). Conversely, in non-cancerous cells obtained from non-malignant tissue adjacent to the tumor, cisPt was significantly more cytotoxic than PtAcD $\left(\mathrm{IC}_{50}\right.$ $98.8 \pm 8.7 \mu \mathrm{M}$ for $P t A c D$ and $\mathrm{IC}_{50} 62.3 \pm 4.5 \mu \mathrm{M}$ for cisPt, $P<0.0001$, after $72 \mathrm{~h}$ treatment, $n=30$ primary cultures) (Figures 1a and b). Thus, epithelial breast cancer cells were more sensitive to PtAcD than normal cells, while the opposite occurred for cisPt.

Induction of apoptosis by $\boldsymbol{P t A c D}$. Cells were treated or not with $10 \mu \mathrm{M} P t A c D$ and $100 \mu \mathrm{M}$ cisPt, concentrations corresponding to the $\mathrm{IC}_{50}$ values in both normal and tumor cells, after $48 \mathrm{~h}$ exposure to agonist (as shown in Figures 1a and b, $10 \mu \mathrm{M}$ PtAcD provokes important cytotoxic effects on cancer but negligible effects on healthy cells), and the cleavage patterns of caspase-3, -7 and -9 were analyzed by western blotting. PtAcD caused the very fast proteolysis of procaspase-7, -9 and PARP in tumor cells and a slower proteolysis in normal cells (Figure 1c). CisPt caused the proteolysis of procaspase-7 and -9 at higher concentration, but it also caused the activation of caspase-3 and PARP proteolysis (Figure 1d). The inhibition of caspase-3 by small interfering RNA (siRNA) provoked a significant decrease in healthy cell death obtained with cisPt, while there was no difference in cells treated with PtAcD (Figures 1e and f), confirming that the apoptotic pathways triggered by $P t A c D$ and cisPt are different.

Exposure of cancer breast cells to PtAcD induced an increase in Bax expression and a pronounced decrease in Bcl-2 expression, while in normal cells are observed less pronounced variations. The truncated form of Bid (t-Bid) was observed only in cancer cells after $3 \mathrm{~h}$ of PtAcD exposure (Figure 1c). CisPt induced an increase in the expression of Bax and a decrease in the expression of $\mathrm{Bcl}-2$, while no effects on the Bid/t-Bid conversion were observed (Figure 1d).

PtACD-induced MAPK phosphorylation. We investigated the effect of PtAcD on the c-Jun N-terminal kinase (JNK) and p38 phosphorylation in both cancer and normal breast cells. By the use of a phospho-specific JNK antibody, we determined that PtAcD-mediated JNK activation was dose-dependent with a threshold effect observed at $1 \mu \mathrm{M}$ and with a maximum at $10 \mu \mathrm{M}$, in both normal and cancer cells (Figure 2a). No further increase was shown at 100 and $200 \mu \mathrm{M}$ of $P t A c D$. Therefore, subsequent experiments were carried out using $10 \mu \mathrm{M} P t A c D$. The effects of $P t A c D$ were time-dependent beginning $1 \mathrm{~h}$ after treatment and persisting through the next $3-24 \mathrm{~h}$ in cancer cells (Figure $2 \mathrm{~b}$, right panel). On the other hand, normal cells showed after $1 \mathrm{~h}$ only a transient JNK activation that declined rapidly over the next 3-6h (Figure 2b, left panel). JNK activation was significantly higher in cancer than in normal cells (Figure 2, lower panel).

The activation of p38 was evaluated by using an antibody against its phosphorylated form ( $p-p 38)$. We observed a threshold effect at $1 \mu \mathrm{M}$ with a maximum at $10 \mu \mathrm{M}$ in both normal and cancer cells (Figure 2a). In cancer cells PtAcD treatment led to sustained activation (from $1-12 \mathrm{~h}$ after treatment) of p38 (Figure 2b, right panel). In normal cells maximal p38 phosphorylation was apparent at $6 \mathrm{~h}$ and then rapidly disappeared over the next $12 \mathrm{~h}$ (Figure $2 \mathrm{~b}$, left panel). During PtAcD treatment the expression of either total (phosphorylated plus un-phosphorylated) JNK or p38 did not change (Figures 2a and b).

The involvement of JNK and p38 signaling in PtAcD cytotoxicity was further studied by the use of inhibitors. Pretreatment with the JNK inhibitor SP600152 resulted in attenuated sensitivity to $P t A c D$, as a significant increase in cell survival and a decrease in caspase-7 activation were observed, in both tumor and normal cells. At $20 \mu \mathrm{M}$ SP600152 the percentage of surviving cells was $85 \%$ in both cell lines, significantly more than in its absence (78 and $45 \%$ in normal and tumor cells, respectively) (Figure 2c). Conversely, pretreatment with the p38 inhibitor SB203580 provoked a significant increase in cell survival from $45-74 \%$ in tumor cells only (ANOVA: $P<0.001$; Figures $2 \mathrm{c}$ and $\mathrm{d}$ ). These findings suggest that the differences in duration and extent of JNK/p38 activation in tumor and normal cells may be linked to survival or apoptosis.

PtAcD increased extracellular regulated kinase 1/2 (ERK1/2) phosphorylation with a maximum at $10 \mu \mathrm{M}$ PtAcD (5.0 and 1.6-fold above basal levels in normal and tumor cells, respectively; Figure 3a). The effect of $10 \mu \mathrm{M} \mathrm{PtAcD}$ on the ERK1/2 phosphorylation was time-dependent. There was a threshold increase at $15 \mathrm{~min}$ and a maximal effect at $1 \mathrm{~h}$ in both normal and tumor cells. Conversely, PtAcD did not have effect on total ERK1/2 levels (Figure 3b). PD98059, a MAPK/ERK kinase (MEK) 1 inhibitor, was used in order to determine whether MEK was involved in PtAcD-induced phosphorylation of ERK1/2. Cell pre-treated with 15 and $30 \mu \mathrm{M}$ PD98059 showed a dose-dependent inhibition of the PtAcD-induced ERK1/2 phosphorylation (Figure 3c). Furthermore, normal cells pretreated with PD98059 showed an increased sensitivity to PtAcD, while in tumor cells PD98059 had no effects (Figure 3c). In the presence of $30 \mu \mathrm{M}$ PD98059 survival was about $50 \%$ in normal cells, significantly less than in the absence of PD98059 (80\%; Figure 3c) and a significant increase in the activated forms of caspase-7 was found (Figure 3c). Thus, the lowest cytotoxicity of PtAcD in normal cells appeared to depend upon the phosphorylation of ERK1/2.

PtAcD-induced Akt activation. PtAcD (1-200 $\mu \mathrm{M})$ caused a dose-dependent phosphorylation of Akt (Figure 3a). In normal and tumor cells, a threshold increase of phosphorylated Akt was observed at $1 \mu \mathrm{M} P t A c D$, with a maximum at $10 \mu \mathrm{M}$ (7.0- and 4.0-fold above basal levels in normal and tumor cells, respectively; $P<0.001$ ANOVA). Thus, subsequent experiments were carried out using $10 \mu \mathrm{M}$ PtAcD. PtAcD caused a transient phosphorylation of Akt in tumor cells, which was maximal at $30 \mathrm{~min}$ and reached the basal 

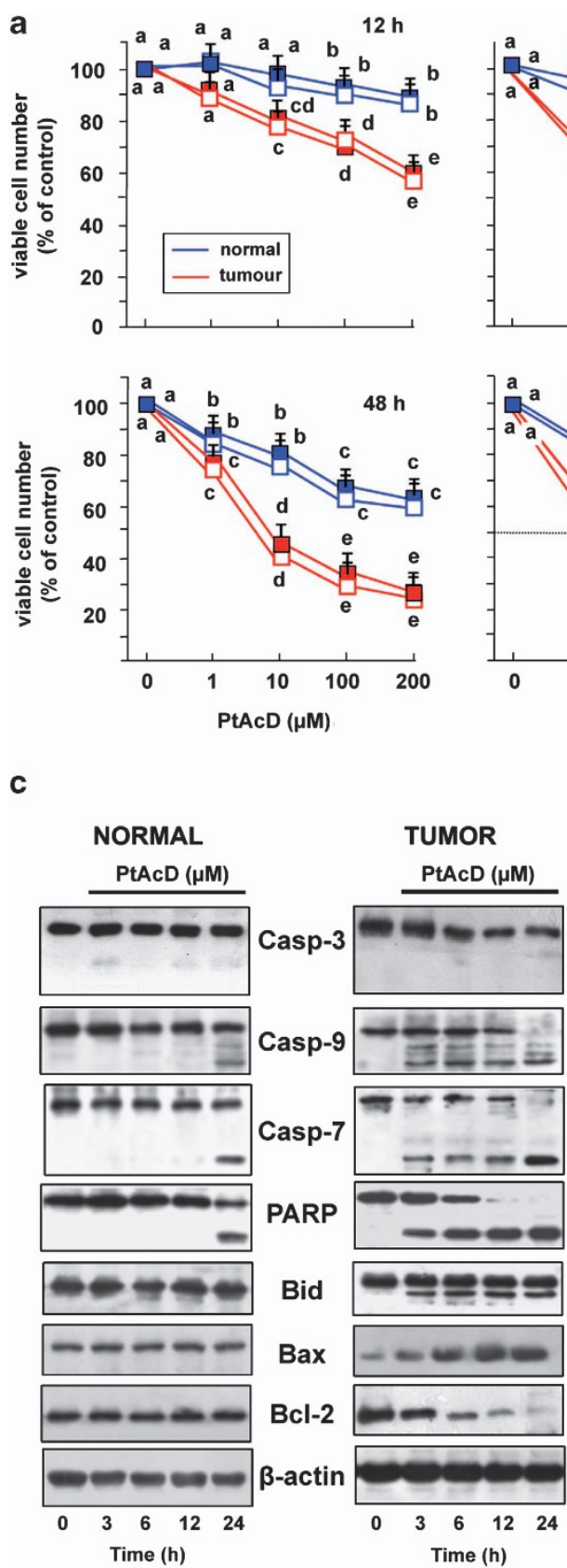
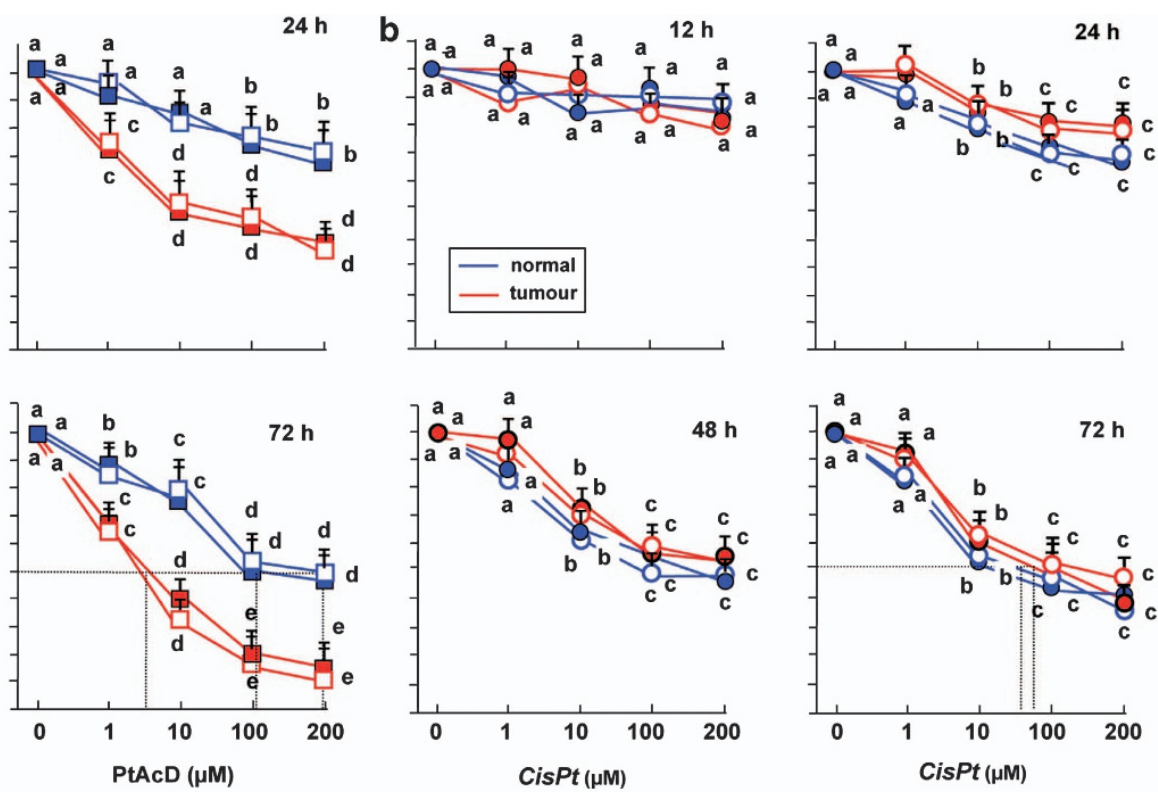

d

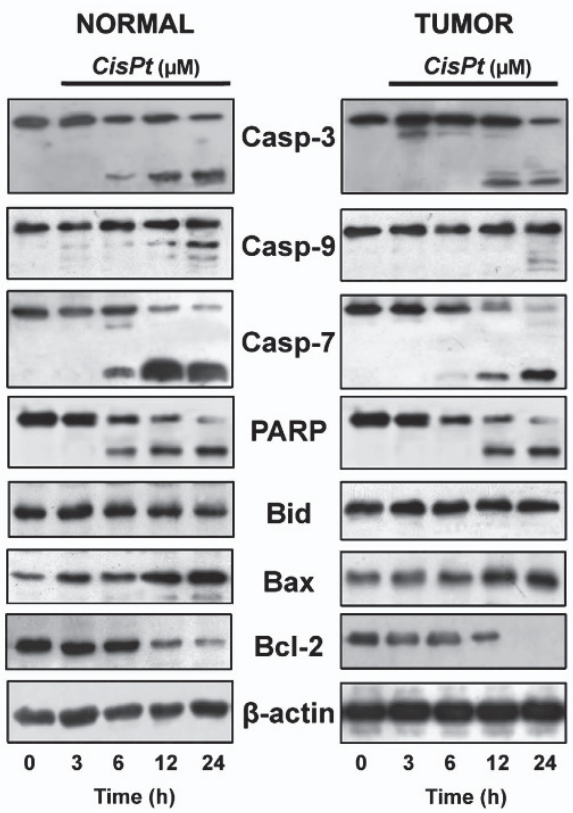

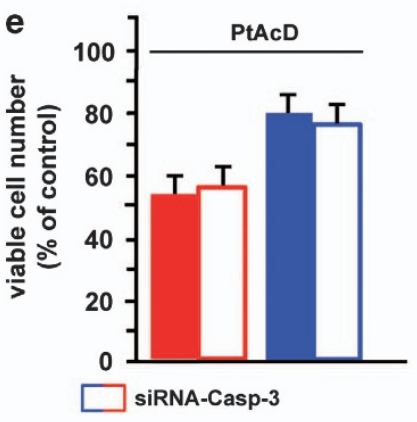

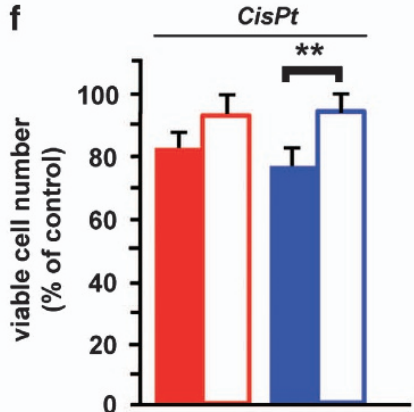

Figure 1 Sensitivity of breast cells to $P t A c D$ and cisPt. Cells were treated with and without increasing concentrations of $P t A c D(\mathbf{a})$ or cisPt (b) and viable cell number was determined 12, 24, 48 and $72 \mathrm{~h}$ later by MTT assay (empty squares and circles) and by cell counting using the trypan blue exclusion assay (filled squares and circles). Data are means \pm S.D. obtained from 30 different breast cancer cells in primary culture and 30 corresponding normal breast epithelial cells in primary culture, both at passages 2-3, with eight replicates in each, and are presented as \% of control. Values with shared letters are not significantly different according to Bonferroni/Dunn post hoc tests. (c and d) Cells were treated or not, for the indicated time, with $10 \mu \mathrm{M} \mathrm{PtAcD}$ and $100 \mu \mathrm{M}$ cisPt (both concentrations corresponding to the IC ${ }_{50}$ values after $48 \mathrm{~h}$ exposure to compounds, see $\mathbf{a}$ and $\mathbf{b}$ ). Cytosolic and nuclear fractions were separated by SDS-PAGE and analyzed by western blotting using monoclonal anti-PARP, anti-caspase-3, -7 and -9 , and $\mathrm{Bid}, \mathrm{Bax}$ and $\mathrm{Bcl} 2$. Sequential incubation with anti- $\beta$-actin confirmed the equal protein loading. These results are representative of four independent experiments carried out on four normal/cancer pairs. (e and f) Viable cell numbers obtained in cells transfected with siRNA-caspase-3, and then incubated with $10 \mu \mathrm{M}$ PtAcD for $24 \mathrm{~h}$. In red are indicated the cancer cells and in blue the normal cells

level after $6 \mathrm{~h}$. In normal cells the phosphorylation of Akt was highest at $30 \mathrm{~min}$ but persisted unchanged up to $24 \mathrm{~h}$ (Figure 3b). Pre-treatment with the phosphatidylinositol 3-kinase (PI3K) inhibitor LY294002 resulted in enhanced sensitivity of the cells to $P t A c D$, inasmuch as a significant decrease in cell survival and an increase of caspase-7 activation were observed, in both normal and tumor cells (Figures $3 c$ and $d$ ). These findings confirm that Akt has a prosurvival role in breast cells treated with $P t A c D$, as in human neuroblastoma cells. ${ }^{8}$ 
a

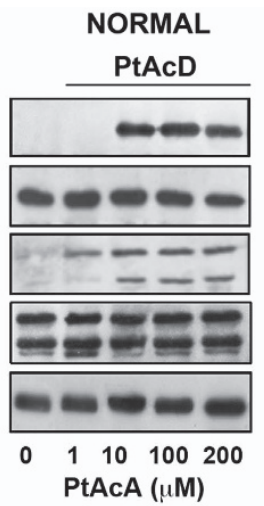

c
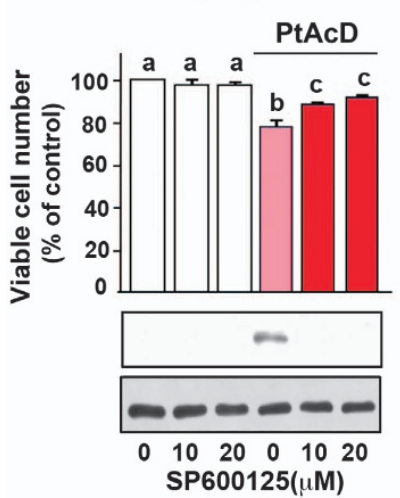

TUMOR

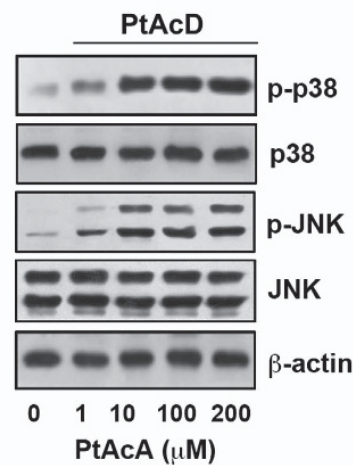

TUMOR
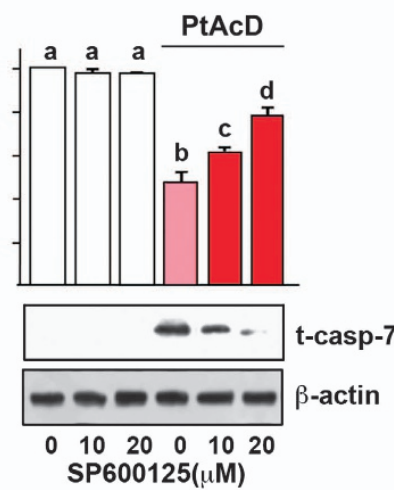

b

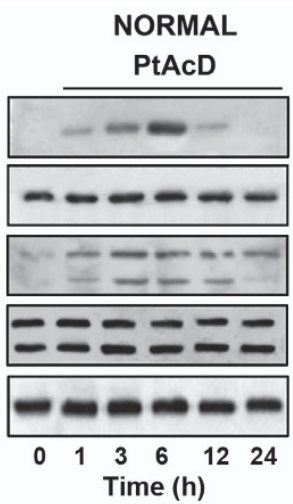

d

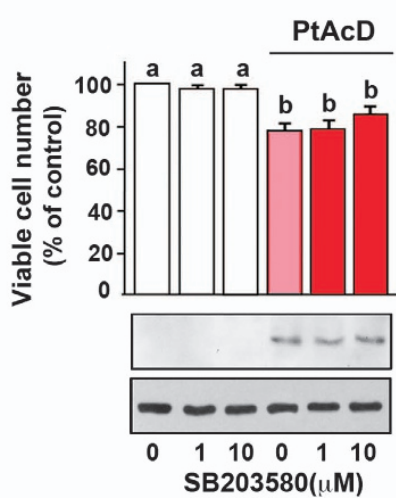

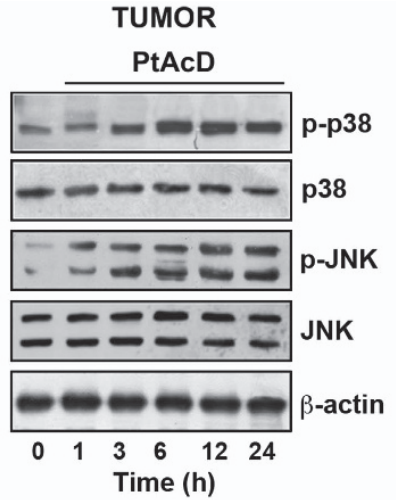

TUMOR

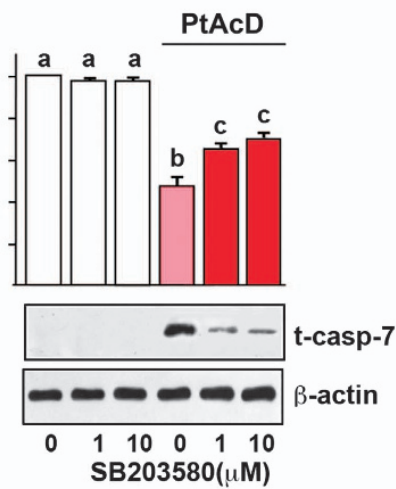

Figure 2 PtAcD induce p38 and JNK1/2 activation in breast cells. Cells were treated or not with increasing concentrations of PtAcD for $6 \mathrm{~h}(\mathrm{a})$ or with $10 \mu \mathrm{M} P t A c D$ for the indicated time (b). Cell lysates were analyzed by western blotting with anti-unphosphorylated and phosphorylated p38MAPK and JNK1/2 antibodies. Sequential incubation of the blots with anti- $\beta$-actin antibody confirmed equal protein loading. Cells pretreated with SB203580 (1-10 $\mu \mathrm{M})$ (c) or with SP600125 (1-10 $\mu \mathrm{M})($ d) were incubated or not with $10 \mu \mathrm{M}$ PtAcD. Viable cell number was determined $24 \mathrm{~h}$ later by MTT assay. Data are means \pm S.D. of four different experiments, with eight replicates in each, and are presented as \% of control. Values with shared letters are not significantly different according to Bonferroni/Dunn post hoc tests. Bottom panel-cell lysates were analyzed by western blotting with antibodies against activated caspase-7 (t-casp-7). Western blotting results are representative of three independent experiments carried out on three normal/cancer pairs. The same blots were stripped and reprobed with an anti- $\beta$-actin monoclonal antibody

The mechanism of PtAcD-induced MAPKs phosphorylation Role of PKC: Previous reports have shown that activation of protein kinase $C$ (PKC) pathways influences the sensitivity of tumor cells to PtAcD., ${ }^{3,8}$ The PKC isozymes expression in primarily cultured epithelial breast cells was previously determined. ${ }^{6}$ Inasmuch as activated PKCs translocate from the cytosol to the cellular membranes, we analyzed, by immunoblotting, the distribution of PKCs in breast cells treated with $10 \mu \mathrm{M} P t A c D$ at different times $(0-80 \mathrm{~min}$ ). Cytosol-to-membrane translocations of PKC- $\alpha$ and PKC- $\zeta$ were observed in both cell types, while PKC- $\delta$ translocated only in tumor cells (Figure 4a). We used molecular (PKC- $\alpha$ siRNA, PKC- $\delta$-siRNA and PKC- $\zeta$-siRNA) techniques in order to specifically inhibit PKC- $\alpha$, PKC- $\delta$ and PKC- $\zeta$ and establish their role in MAPKs control. Preliminary experiments by western blotting demonstrated that PKC- $\alpha$-siRNA, PKC- $\delta$-siRNA and PKC- $\zeta$-siRNA decreased PKC- $\alpha$, PKC- $\delta$ and PKC- $\zeta$ expressions and that not specific siRNA (siRNANS) had no silencing effect (Figure 4b). The inhibition of PKC- $\zeta$ (Figure 4c) completely blocked PtAcD-provoked JNK and p38 phosphorylation in normal breast cells, and only partially in tumor cells (Figure 4d). In fact, in tumor cells the complete inhibitions of the p38 and JNK phosphorylation were observed when both PKC- $\zeta$ and PKC- $\delta$ expressions were silenced (Figure $4 d$ ). The results suggested that PKC- $\delta$ is responsible for sustained phosphorylation of p38 and JNK. Pre-treatment of cells with PKC- $\alpha$-siRNA (10 nM) inhibited both PtACD-induced ERK1/2 and Akt phosphorylation and also epidermal growth factor receptor (EGFR) internalization in both normal and tumor breast cells (Figure $5 \mathrm{c}$ ).

Role of EGFR: We showed previously that in thyroid cells cisPt activated ERK1/2 through the EGFR pathway; ${ }^{9}$ thus, here we determined the role of the EGFR pathway in breast cells treated with $P t A c D$. Ten $\mu \mathrm{M} P t A c D$ induced changes in EGFR cellular localization due to internalization (Figure 5a). The EGFR internalization and the PtAcD-provoked ERK1/2 and Akt phosphorylation were completely blocked by pre-incubation with the EGFR inhibitor AG1478 (15-30 $\mu \mathrm{M}$; Figure 5b). AG1478 also enhanced the sensitivity of both normal and tumor cells to PtAcD (Figure 5d), indicating that the EGFR pathway is involved in cell survival after PtAcD treatment.

Role of ROS: PtAcD increased the synthesis of ROS in cancer cells., 80,11 Using the nitroblue tetrazolium (NBT) assay we also found that in normal and tumor cells PtAcD 

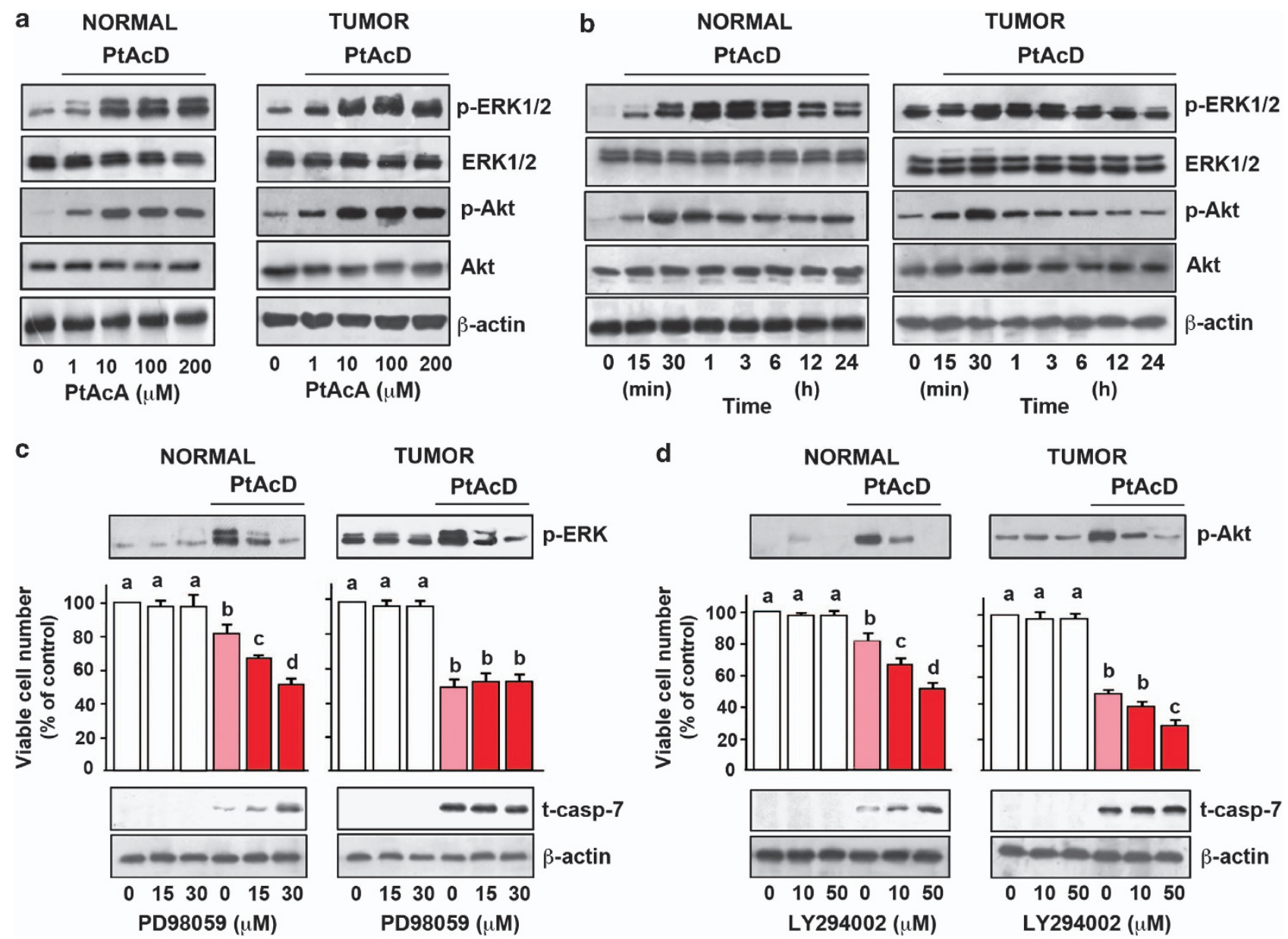

Figure 3 PtAcD induces Akt, and ERK1/2 activation in breast cells. Cells were treated or not with increasing concentrations of $P$ tAcD ( $1 \mathrm{~h}$ for ERK or 30 min for Akt phosphorylation) (a) or with $10 \mu \mathrm{M}$ PtAcD for the indicated time (b). Cell lysates were analyzed by western blotting with anti-unphosphorylated and phosphorylated Akt and ERK1/2 antibodies. Sequential incubation of the blots with anti- $\beta$-actin antibody confirmed equal protein loading. Cells pretreated with PD98059 (1-30 $\mu \mathrm{M})(\mathbf{c})$ or with LY294002 (10-50 $\mu \mathrm{M})(\mathrm{d})$ were incubated or not with $10 \mu \mathrm{M}$ PtAcD. Viable cell number was determined $24 \mathrm{~h}$ later by MTT assay. Data are means \pm S.D. of four different experiments, with eight replicates in each, and are presented as \% of control. Values with shared letters are not significantly different according to Bonferroni/Dunn post hoc tests. Bottom panel - cell lysates were analyzed by western blotting with antibodies against activated caspase-7 (t-casp-7). Western blotting results are representative of three independent experiments carried out on three normal/cancer pairs. The same blots were stripped and reprobed with an anti- $\beta$-actin monoclonal antibody

significantly increased the level of ROS in a time-dependent manner (ANOVA: $P<0.05$; Figure 6a). ROS generation by $P t A c D$ was higher in cancer than in normal cells. Diphenyleneiodonium (DPI), an inhibitor of the NAD(P)H oxidase, and apocynin, inhibited the PtAcD-induced PKC- $\alpha$ translocation, EGFR activation and ERK1/2 and Akt phosphorylations (Figure $6 b$ ), suggesting the involvement of $\mathrm{NAD}(\mathrm{P}) \mathrm{H}$ oxidase in these cell survival pathways. Among the members of the $\mathrm{NAD}(\mathrm{P}) \mathrm{H}$ oxidase (NOX) family, NOX1, NOX4 and NOX5 are coexpressed in breast epithelial cell line and primary breast tissues. ${ }^{12}$ As Noxes have a requirement for the transmembrane protein $\mathrm{p} 22^{\text {phox }}$, we evaluated $\mathrm{p} 22^{\text {phox }}$ protein levels in five normal/cancer pairs. Figure $6 \mathrm{c}$ shows that $\mathrm{p} 22^{\text {phox }}$ protein levels are higher in tumors and this may be an indication that cancer cells can respond to PtAcD generating higher levels of ROS compared with healthy cells.

As JNK and p38 activation is required for PtAcD-induced apoptosis, we analyzed whether inhibition of the antiapoptotic pathways had an effect on these kinases. Indeed, LY294002 and PD98059 enhanced PtAcD-induced activation of p38 and JNK1/2 in both normal and tumor cells (Figure 6d).

\section{Discussion}

One major challenge in anticancer therapy is to increase the selectivity of current treatments toward cancer cells in order to spare normal cells. We have previously demonstrated that $P t A c D$ possesses a greater cytotoxicity than cisPt in human cancer cells. ${ }^{3,5,8}$ Differently from cisPt, for which the activity appears to be associated both with its intracellular accumulation and with the formation of DNA adducts, the cytotoxicity of this new compound is related to the intracellular accumulation only, showing a low reactivity with nucleobases and a specific reactivity with sulfur ligands. The different mechanism of action of PtAcD may render it intrinsically able to evoke less chemoresistance. ${ }^{3,5}$ PtAcD exhibited higher antitumor activity than cisPt also in breast cancer cell lines relatively resistant to many chemotherapeutic agents, cisPt included. ${ }^{13}$ 

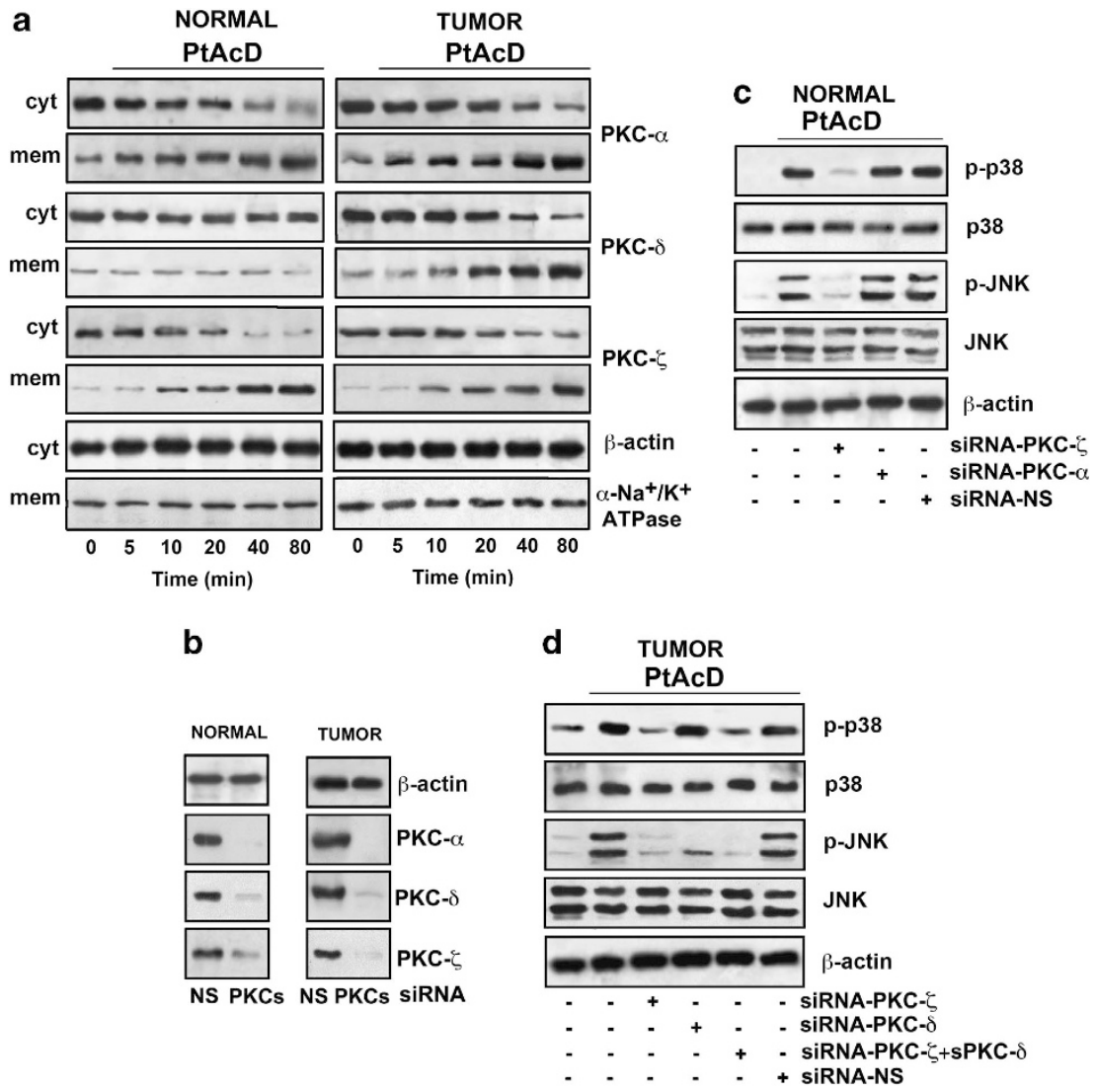

Figure 4 Roles of PKCs in PtAcD-treated cells. (a) Cells were treated without or with $10 \mu \mathrm{M} \mathrm{PtAcD} \mathrm{for} \mathrm{the} \mathrm{indicated} \mathrm{times.} \mathrm{For} \mathrm{PKCs} \mathrm{translocation} \mathrm{studies,} \mathrm{cytosol} \mathrm{(cyt)}$ and membrane (mem) fractions were analyzed by western blotting with specific antibodies. The purity of fractions was tested with anti- $\beta$-actin and anti- $\alpha$ subunit of Na ${ }^{+} /$ $\mathrm{K}^{+}$ATPase monoclonal antibodies. The figures are representative of four independent experiments. Cells were transfected with siRNA-PKC- $\alpha$, -PKC- $\delta$ and - PKC- $\zeta$ or with control siRNA (NS) and then were incubated with $10 \mu \mathrm{M} P t A c D$. Western blotting of total lysates was performed with specific anti-PKCs (b), or with anti-unphosphorylated and phosphorylated P38MAPK, and JNK1/2 antibodies (c and d). Western blotting results are representative of four independent experiments carried out on four normal/cancer pairs

As the normal breast cells MCF-10A were less sensitive to $P t A c D$ than cancerous breast cells, it becomes important to establish whether effectively $\operatorname{PtAcD}$ is especially toxic to cancer cells. To this end, the effects of PtAcD were studied in primary cultured epithelial tumor and normal breast cells obtained from histologically proven malignant and nonmalignant tissue. The cytotoxicity of $P t A c D$ was stronger in tumor than in normal breast cells. PtAcD showed 18-20-fold higher selectivity in killing cancer over normal cells. PtAcD cytotoxicity in tumor cells was approximately 16-fold higher than that observed for cisPt, which does not have selectivity toward breast cancer cells. PtAcD was able to activate the mitochondrial apoptotic pathway in both cell types, although with different extent, as already demonstrated in immortalized cells. ${ }^{5,8}$

Activated MAPKs are components of the apoptotic program $^{7}$ and we showed previously that p38 and JNK contributes to the apoptosis provoked by PtAcD in SH-SY5Y human neuroblastoma cells. ${ }^{8}$ Several data suggested that JNK and p38 may have different (cell death-cell proliferation) and sometimes opposite (cell proliferation-cell proliferation arrest) biological activities depending on the cell type and stimulus. We therefore investigated the activation of JNK and p38, their respective upstream intracellular activators and the effects of inhibiting their activation in PtAcD-treated breast cells. PtAcD differentially activated JNK and p38: such activation is prolonged and strong in tumor cells whereas transient and of the small intensity, in normal cells. Previous studies have established that Jnk1 and Jnk2 genes are implicated in the developmental morphogenesis of mammary gland. Bim and Bmf are targets of proapoptotic signaling by JNK. ${ }^{14}$ On the other hand, JNK signaling loss may lead to defects in Bim/Bmf function and consequently to failure of luminal clearance. ${ }^{15}$ In the setting of breast cancer development, JNK deficiency increased tumor formation and JNK activation-defective cell lines are resistant to the lethal effects of cisPt ${ }^{16}$ Consistently, our results showed that JNK plays a much more important role than p38 in PtAcD-induced apoptosis of tumor cells. However, the physiological function of JNK does not necessarily include induction of apoptosis. ${ }^{17}$ Another study revealed different biological consequences of JNK, depending on the time of activation after UV light exposure or genotoxic agent. ${ }^{18}$ The same was true for p38, although the effect was less pronounced than that of JNK. It is interesting to note that the different times and duration of the activation of JNK and p38 can alter their outcome on the 

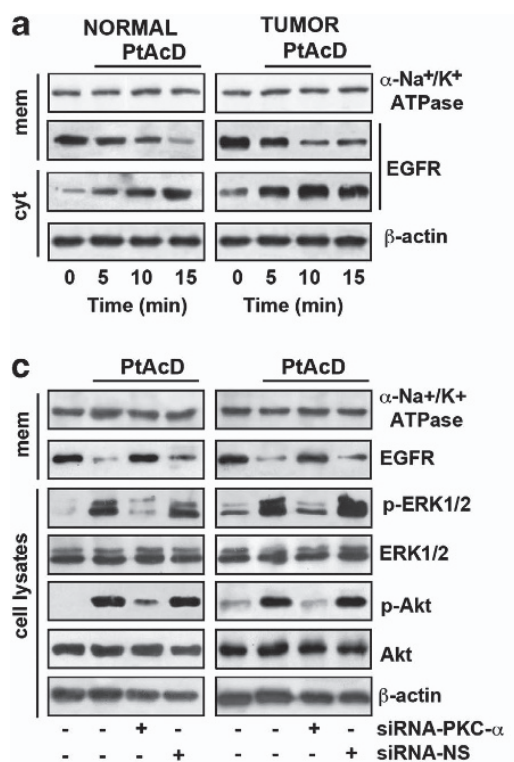

b

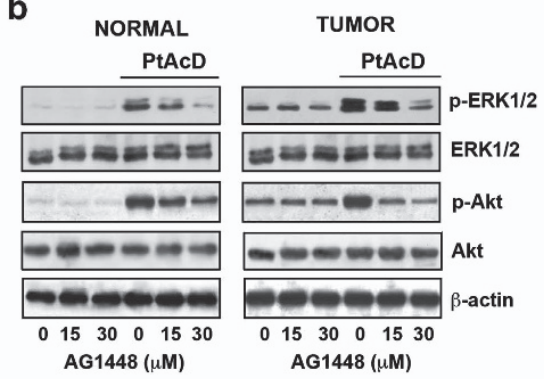

d

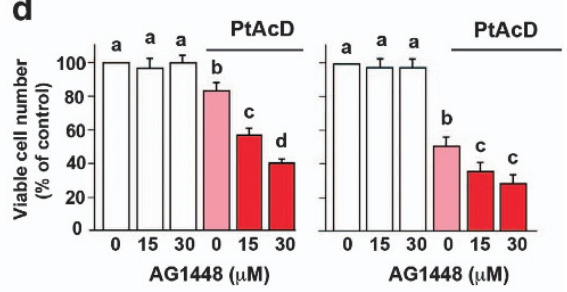

Figure $5 P t A c D$ induces EGFR transactivation. (a) Cells were treated or not with PtAcD for the indicated time and cytosolic and membrane fractions were analyzed by western blotting with anti-EGFR antibody. The purity of fractions was tested with the anti- $\beta$-actin and anti- $\alpha$ subunits of $\mathrm{Na}^{+} / \mathrm{K}^{+}$ATPase monoclonal antibodies. (b and $\left.\mathbf{d}\right)$ Cells were pretreated or not with EGFR inhibitor, AG1478, and then with $P t A c D$ for $24 \mathrm{~h}$. Cell lysates were analyzed by western blotting with anti-unphosphorylated and phosphorylated Akt and ERK1/2 antibodies. Sequential incubation of the blots with anti- $\beta$-actin antibody confirmed equal protein loading (b). Viable cell number was determined $24 \mathrm{~h}$ later by MTT assay (d). Data are means \pm S.D. of four different experiments, with eight replicates in each, and are presented as $\%$ of control. Values with shared letters are not significantly different according to Bonferroni/Dunn post hoc tests. (c) Cells were transfected with siRNA-PKC- $\alpha$ or with control siRNA (NS) and then were incubated with $10 \mu \mathrm{M} P t A C D$. Western blotting of total lysates was performed with specific anti-EGFR, or with anti-unphosphorylated and phosphorylated ERK1/2 and Akt antibodies. Western blotting results are representative of three independent experiments carried out on three normal/cancer pairs

proliferation, differentiation or apoptosis. ${ }^{19}$ In addition, in cell lines resistant to cisPt a sustained activation of JNK and p38 represents a general mechanism of apoptosis. ${ }^{20}$ Also our results show that the long activation of JNK and p38 is responsible for the death of cancer cells induced by PtAcD. In normal cells, the cytotoxic effect of $P t A c D$ was smaller and correlated with the transient activation of $\mathrm{p} 38$. Although further studies are needed to identify the specific intracellular targets of $\mathrm{JNK} / \mathrm{p} 38$, here we anticipate that cisPt causes the sustained phosphorylation of JNK and p38 and that this persistent activation is associated with apoptosis of both tumor and healthy breast cells.

It has been demonstrated that ERK1/2 signaling pathway is activated in response to certain cellular stresses, cisPt and $P t A c D$ included. ${ }^{3,8,10}$ ERK activation may exert either an antiapoptotic ${ }^{21}$ or a proapoptotic ${ }^{22}$ influence depending upon the cellular context and by as yet unclarified regulatory mechanisms. In breast cells, PtAcD provoked high and sustained activation of ERK1/2. The increase in apoptotic cell number and decrease in caspase-7 activation found under conditions in which ERK1/2 phosphorylation was inhibited, suggested an antiapoptotic role of ERK $1 / 2$ in normal cells only. This discrepancy between healthy and cancerous cells indicated that ERK1/2 activity in response to $P t A c D$ treatment might depend on the individual cellular context, and that ERK1/2 in tumor cells has somehow lost its antiapoptotic role. Preliminary data obtained in breast tumor cells showed a drastic impairment of cell motility in response to $P t A c D$ occurring through a novel mechanism mediated by ERK $1 / 2$ activation. The signaling molecules upstream of MAPKs, likely different in the two cell types, may explain the different effects on their phosphorylation state.

In both PtAcD- and cisPt-induced effects, PKCs are crucial elements in the pathway linking $\mathrm{Pt}(\mathrm{II})$ compounds to MAPK cascades. ${ }^{3,10}$ Here, atypical PKC- $\zeta$ is required for the transient phosphorylation of $\mathrm{p} 38$ and JNK after PtAcD treatment. This is particularly intriguing because $\mathrm{PKC}-\zeta$ can be activated by mitogenic and apoptotic stimuli and interactions between PKC- $\zeta$ and the pro-mitogenic cascades have been suggested. ${ }^{23}$ Recent studies have demonstrated a growth inhibitory role for $\mathrm{PKC}-\zeta$, its involvement and increased expression during apoptosis. ${ }^{24,25}$ In tumor cells the persistent and prolonged activation of JNK and p38 is made possible because, the initial action of $\mathrm{PKC}-\zeta$, is supported by the concurrent activation of PKC- $\delta$. Probably, this is necessary to overcome a certain threshold level required to trigger the activation of factors required for apoptosis. Similar results were reported in PtAcD-treated SHSY5Y human neuroblastoma cells and during apoptosis in salivary gland acinar cells and in prostate cancer cells. ${ }^{26,27}$ Conversely, PKC- $\alpha$ is responsible for the normal breast cell survival. PKC- $\alpha$ activated downstream signaling pathways including EGFR, ERK and PI3K/AKT, as both ERK1/2 and Akt phosphorylation are blocked by siRNA-PKC- $\alpha$. Regarding Akt, one of the most important factors for cell survival in response to different stress, ${ }^{28}$ it exerts its antiapoptotic role in both normal and tumor breast cells.

Many chemotherapeutic agents have effects on the cellular redox status; ${ }^{29}$ we showed that $P t A c D$ increased the synthesis of ROS through activation of $\mathrm{NAD}(\mathrm{P}) \mathrm{H}$ oxidase and 
a
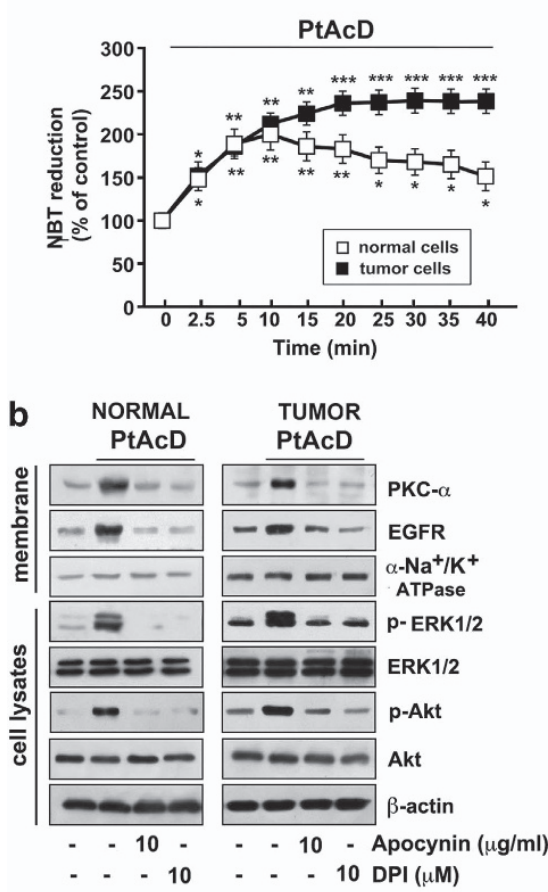
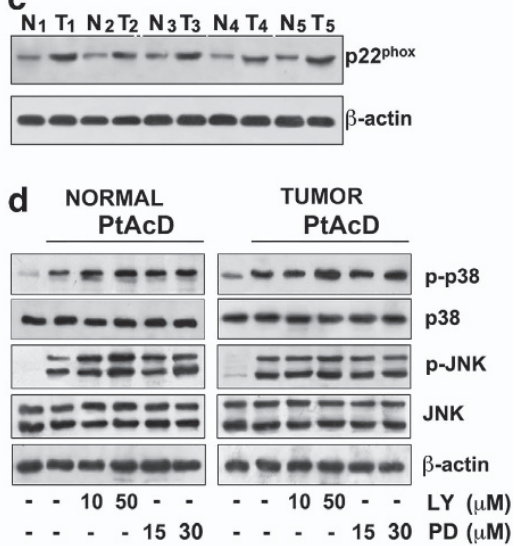

e

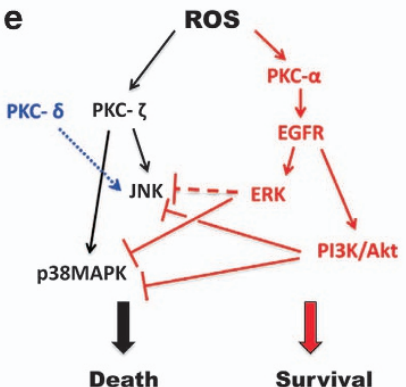

Figure 6 PtACD induces ROS generation. (a) Cells were exposed to $10 \mu \mathrm{M} \mathrm{PtAcD}$ for the indicated times. ROS production was measured by NBT reduction. Asterisks indicate values that are significantly different between normal and tumor cells at the same time point $\left({ }^{\star} P<0.05 ;{ }^{* *} P<0.01 ;{ }^{* * *} P<0.001\right)$. (b and $\left.\mathbf{d}\right)$ Cells pre-incubated with apocynin or with DPI (b) PD98059 or LY294002 (d) for 30 min were exposed to $10 \mu \mathrm{M}$ PtAcD. Membrane fractions (mem) (b) or cell lysates (d) were analyzed by western blotting with specific anti-PKC- $\alpha$, anti-EGFR antibodies or with anti-phosphorylated or anti-total (unphosphorylated and phosphorylated) ERK1/2, Akt, p38 and JNK antibodies. PD stands for PD98059 and LY for LY294002. The purity of fractions was tested with anti- $\alpha$ subunit of $\mathrm{Na}^{+} / \mathrm{K}^{+}$ATPase or anti- $\beta$-actin monoclonal antibodies. (c) Cell lysates were analyzed by western blotting with anti p22 ${ }^{\text {phox }}$ antibody in five cultured cancerous $(\mathrm{T})$ and corresponding normal $(\mathrm{N})$ human breast epithelial cells. Sequential incubation of the blots with anti- $\beta$-actin antibody confirmed equal protein loading. Western blotting results are representative of five independent experiments carried out on five normal/ cancer pairs. (e) Crosstalk between ERK/Akt and p38/JNK pathways, key factors affecting cell death and survival in PtAcD-treated breast cells

mitochondrial pathways. ${ }^{8,10,11}$ It is known that PtAcD causes the increase in ROS mainly through the activation of $\mathrm{NAD}(\mathrm{P}) \mathrm{H}$ oxidase, though its exact mechanism of action is still elusive. ROS generation can regulate the cell-fate decision through the control of many functional proteins. ${ }^{30}$ Here, redox regulation is twofold; ROS affected key factors controlling cell death and survival. Whether the consequence of oxidative stress will lead to cell survival or death is likely dependent on the integration of those ROS-sensitive signals. In our case p38 and ERK/Akt activation were linked to PKC- $\zeta$ and PKC- $\alpha$, respectively. The activation of $\mathrm{PKC}-\zeta$ and $\mathrm{PKC}-\alpha$ provoked by PtAcD was due to ROS as such activations were blocked by inhibiting the $\mathrm{NAD}(\mathrm{P}) \mathrm{H}$ oxidase. Thus, $\mathrm{NAD}(\mathrm{P}) \mathrm{H}$ oxidase activation leading to MAPKs activation is a key event in the apoptotic processes but also in the survival process after exposure of the breast cells to PtAcD. The overall effect was different in the two different cell types, also because in cancer cells there was a significantly greater production of ROS. The levels and durations of ROS determined the activation or inhibition of each signal-transduction pathway. The inhibition of PI3K made stronger the action of p38 and JNK, as previously shown in neuroblastoma cells. $^{8}$

In summary, PtAcD causes the activation of the classical pro-survival pathways PI3K and ERK1/2 that, particularly in normal cells, have an important role in the block of apoptotic processes that are only secondarily activated. In cancer cells $P t A c D$ also activated PKC- $\delta$ responsible for the sustained activation of p38 and JNK, both involved in the apoptotic process; in addition in cancer cells ERK1/2 lost its antiapoptotic role.

\section{Conclusion}

These studies support our assumption of higher toxicity of PtAcD toward cancer cell previously observed in immortalized breast cell lines. We confirm the potent and selective cytotoxic effects against breast cancer cells in primary cultures. $P t A c D$ produces these effects at concentrations lower than cisPt, whose undesirable side effects continue to limit its effectiveness. The selectivity of the observed effects stimulates a more detailed study to understand the balance of cellular and molecular mechanisms involved, in addition to pre-clinical investigation of the therapeutic potential of $P t A c D$ in vivo.

Materials and Methods

Primary culture of breast epithelial cells. Thirty breast cancer tissues and the corresponding histologically proven non-malignant tissue adjacent to the 
tumor were obtained after surgery performed in the 'V. Fazzi' hospital (Lecce). All patients gave informed consent to study participation before enrolment. All the tumors were invasive intraductal carcinomas from patients who fulfilled the following inclusion criteria: having a breast lesion pathologically diagnosed as malignant by core biopsy, not having received any therapy before surgery, not pregnant at the time of diagnosis and having no history of breast cancer or previous breast surgery including breast implants. Clinical and pathological data, obtained from hospital archives, are summarized in Table 1.

Portions of tissue were immediately sent to the histopathology laboratory for the histological diagnosis, and other portions placed into transport medium and disaggregated immediately as described previously. ${ }^{31}$

The cultured cells exhibited the characteristic features of epithelial cells, that is, a positive immunocytochemical staining for cytokeratin 19; the contamination from fibroblasts was quantified by using anti-Vimentin antibody (Sigma, Milan, Italy), showing that their expression was lower than $5 \%$.

We used, for all the experiments shown herein, normal and corresponding tumor breast epithelial cells in primary culture at passages 2-3 as we found that the estrogen receptor $(\mathrm{ER})$ and progesterone receptor $(\mathrm{PgR})$ concentrations, specific markers of the epithelial source of the breast cells, did not change significantly until the fourth culture passages.

Enzyme immunoassay (EIA) of estrogen and progesterone receptors (ER and PgR). ER EIA and PgR ElA assays (Abbott, Chicago, IL, USA) were carried out in accordance with the manufacturer's instructions.

Cytotoxicity assay. We evaluated the $\mathrm{IC}_{50}$ in all pairs of cultures $(n=30$ normal/cancer pairs) with MTT and SRB assays, and by cell counting. The SRB assay and the conversion of MTT by breast cells were used as an indicator of cell number as described previously. ${ }^{3}$ Viable cells were also counted by the trypan blue exclusion assay and light microscopy.

ROS measurements. Experiments on ROS generation were made on five randomly chosen normal/cancer pairs. ROS generation was detected by NBT assay as previously described. ${ }^{5}$

siRNA and siRNA transfection. Small interfering RNAs were prepared by an in vitro transcription method, according to the manufacturer's protocol (Promega, Madison, WI, USA). Initially, four siRNA target sites specific to human caspase-3, PKC- $\alpha$, PKC- $\zeta$ and PKC- $\delta$ mRNA and five siRNA to p65, as determined by blast analysis, were chosen. For each siRNA, sense and antisense templates were designed based on each target sequence and partial $\mathrm{T} 7$ promoter sequence. The breast cells were transfected with siRNA duplexes using the protocol supplied with the CodeBreaker siRNA transfection reagent (Promega) as described previously. ${ }^{32}$

Table 1 Clinicopathologic data of 30 patients in this study

\begin{tabular}{llcl}
\hline Clinicopathologic & Variables & Patients & $\%$ \\
\hline Patient's age & $\leq 50$ & 9 & 30 \\
Menopause & $\geq 50$ & 21 & 70 \\
& Pre & 11 & 36.7 \\
Tumor size & Post & 19 & 63.3 \\
& $\leq 2 \mathrm{~cm}$ & 18 & 60 \\
Histologic grade & $>2 \mathrm{~cm}$ & 12 & 40 \\
& Low (grade 1-2) & 21 & 70 \\
Lymph node metastasis & High (grade 3) & 9 & 30 \\
& Negative & 19 & 63.3 \\
ER status & Positive & 11 & 36.7 \\
& Negative & 7 & 23.3 \\
PR status & Positive & 23 & 76.7 \\
& Negative & 10 & 33.3 \\
HER2 status & Positive & 20 & 66.7 \\
Triple negativity & Negative & 26 & 86.7 \\
Ki-67 & Positive & 4 & 13.3 \\
& Yes & 4 & 13.3 \\
& No & 26 & 86.7 \\
& $\leq 25 \%$ & 22 & 77.3 \\
& $\geq 25 \%$ & 8 & 26.7 \\
\hline
\end{tabular}

Cell lysis, fractionation and western immunoblot analysis. Because of the great demand for material and little availability of cultured cells western blotting experiments were done on groups of three or four pairs randomly chosen. Specifically, (i) western blottings for caspases, PARP, Bid, Bax and Bcl-2 were made on four pairs, (ii) western blottings for $\mathrm{p38}$ and JNK were done on three pairs, (iii) western blottings for Akt and ERK were done on three pairs; (iv) western blottings for PKC were performed on four pairs and finally (v) the western blottings for EGFR on three other pairs. Preparation of subcellular fraction, western blotting analysis and immunodetection were performed as previously reported. ${ }^{8}$

Statistical analysis. Experimental points represent means \pm standard deviation (S.D.) of 3-6 replicates. Statistical analysis was carried out using the ANOVA. A $P$ value less than 0.05 was considered to achieve statistical significance.

Reagents. PtACD was prepared according to previously reported procedures. ${ }^{3}$ RPMI 1640 medium, antibiotics, glutamine and fetal bovine serum were purchased from Celbio (Pero, Ml, Italy).

Caspase-7, -9 and -3 , Bax, Bid, poly(ADP-ribose) polymerase (PARP), Bcl-2, phospho-specific p-Akt (Ser473) and total Akt, phospho-specific p-ERK1/2 and total ERK1/2, phospho-specific p-p38(Thr180/Tyr182) and total p38 antibodies were obtained from Cell Signalling Technology (Celbio, Milan, Italy).

Phospho-specific p-JNK (Thr183/Tyr185) and total (phosphorylated and unphosphorylated) JNK antibodies were obtained from Sigma. PKC isoforms antibodies, monoclonal p22phox antibody, polyclonal unphosphorylated EGFR antibodies, antihistone-3/4 antibodies, goat anti-rabbit conjugated with peroxidase, as well as control antibodies, were obtained from Santa Cruz Biotechnology (Santa Cruz, CA, USA). All others reagents were from Sigma.

\section{Conflict of Interest}

The authors declare no conflict of interest.

Acknowledgements. The work presented was supported by the Italian Ministry of Research and University (PRIN. 2009).

1. Farrell N. Current status of structure-activity relationships of platinum anticancer drugs. Activation of the trans geometry. Met lons Biol Syst 1996; 32: 603-639.

2. De Pascali SA, Papadia P, Ciccarese A, Pacifico C, Fanizzi FP. First examples of $\beta$-diketonate platinum II complexes with sulfoxide ligands. Eur J Inorg Chem 2005; 5: 788-796

3. Muscella A, Calabriso N, De Pascali SA, Urso L, Ciccarese A, Fanizzi FP et al. New platinum(II) complexes containing both an $0,0^{\prime}$-chelated acetylacetonate ligand and a sulfur ligand in the platinum coordination sphere induce apoptosis in HeLa cervical carcinoma cells. Biochem Pharmacol 2007; 74: 28-40.

4. Cerri S, Piccolini VM, Santin G, Bottone MG, De Pascali SA, Migoni D et al. The developmental neurotoxicity study of platinum compounds. Effects of cisplatin versus a novel Pt(II) complex on rat cerebellum. Neurotoxicol Teratol 2011; 33: 273-281.

5. Muscella A, Calabriso N, Fanizzi FP, De Pascali SA, Urso L, Ciccarese A et al. [Pt(O,O'-acac) $(\gamma$-acac)(DMS)], a new Pt compound exerting fast cytotoxicity in MCF-7 breast cancer cells via the mitochondrial apoptotic pathway. Br J Pharmacol 2008; 153: 34-49.

6. Greco S, Elia MG, Muscella A, Romano S, Storelli C, Marsigliante S. Bradykinin stimulates cell proliferation through an extracellular-regulated kinase 1 and 2-dependent mechanism in breast cancer cells in primary culture. J Endocrinol 2005; 186: 291-301.

7. Fan M, Chambers TC. Role of mitogen-activated protein kinases in the response of tumor cells to chemotherapy. Drug Res Updat 2001; 4: 253-267.

8. Muscella A, Calabriso N, Vetrugno C, Fanizzi FP, De Pascali SA, Marsigliante S. The signalling axis mediating neuronal apoptosis in response $\left[\mathrm{Pt}\left(\mathrm{O}, \mathrm{O}^{\prime}\right.\right.$-acac $)$ $(\gamma$-acac)(DMS)]. Biochem Pharmacol 2011; 81: 1271-1285.

9. Muscella A, Urso L, Calabriso N, Vetrugno C, Fanizzi FP, Storelli $C$ et al. Functions of epidermal growth factor receptor in cisplatin response of thyroid cells. $\mathrm{Br} J$ Pharmacol 2009; 77: 979-992.

10. Muscella A, Calabriso N, Vetrugno C, Urso L, Fanizzi FP, De Pascali SA et al. Sublethal concentrations of the platinum(II) complex $\left[\mathrm{Pt}\left(0, \mathrm{O}^{\prime}\right.\right.$-acac $)(\gamma$-acac)(DMS)] alter the motility and induce anoikis in MCF-7 cells. $\mathrm{Br} J$ Pharmacol 2010; 160: 1362-1377.

11. Muscella A, Calabriso N, Vetrugno C, Fanizzi FP, De Pascali SA, Storelli $C$ et al. The platinum (II) complex $\left[\mathrm{Pt}\left(0, \mathrm{O}^{\prime}\right.\right.$-acac $)(\gamma$-acac)(DMS)] alters the intracellular calcium homeostasis in MCF-7 breast cancer cells. Biochem Pharmacol 2011; 81: 91-103. 
12. Graham KA, Kulawiec M, Owens KM, Li X, Desouki MM, Chandra D et al. NADPH oxidase 4 is an oncoprotein localized to mitochondria. Cancer Biol Ther 2010; 10: 223-231.

13. Blanc C, Deveraux QL, Krajewski S, Jänicke RU, Porter AG, Reed JC et al. Caspase-3 is essential for procaspase-9 processing and cisplatin-induced apoptosis of MCF-7 breast cancer cells. Cancer Res 2000; 60: 4385-4390.

14. Hubner A, Cavanagh-Kyros J, Rincon M, Flavell RA, Davis RJ. Functional cooperation of the proapoptotic Bcl2 family proteins Bmf and Bim in vivo. Mol Cell Biol 2010; 30: 98-105.

15. Zhan L, Rosenberg A, Bergami KC, Yu M, Xuan Z, Jaffe AB et al. Deregulation of scribble promotes mammary tumorigenesis and reveals a role for cell polarity in carcinoma. Cell 2008; 135: 865-878.

16. Zanke BW, Boudreau K, Rubie E, Winnett E, Tibbles LA, Zon L et al. The stress-activated protein kinase pathway mediates cell death following injury induced by cis-platinum, UV irradiation or heat. Curr Biol 1996; 6: 606-613.

17. Davis R. Signal transduction by the JNK group of MAP kinases. Cell 2000; 103: 239-252.

18. Christmann M, Tomicic MT, Aasland D, Kaina B. A role for UV-light-induced C-Fos: stimulation of nucleotide excision repair and protection against sustained JNK activation and apoptosis. Carcinogenesis 2007; 28: 183-190.

19. Nagata $Y$, Todokoro K. Requirement of activation of jnk and p38 for environmental stressinduced erythroid differentiation and apoptosis and of inhibition of Erk for apoptosis. Blood 1999; 94: 853-863

20. Brozovic A, Fritz G, Christmann M, Zisowsky J, Jaehde U, Osmak M et al. Long-term activation of SAPK/JNK, p38 kinase and fas-L expression by cisplatin is attenuated in human carcinoma cells that acquired drug resistance. Int J Cancer 2004; 112: 974-985.

21. Bueno OF, De Windt LJ, Tymitz KM, Witt SA, Kimball TR, Klevitsky R et al. The MEK1-ERK1/2 signaling pathway promotes compensated cardiac hypertrophy in transgenic mice. EMBO J 2000; 19: 6341-6350.

22. Persons DL, Yazlovitskaya EM, Pelling JC. Effect of extracellular signal-regulated kinase on p53 accumulation in response to cisplatin. J Biol Chem 2000; 275: 35778-35785.

23. Muscella A, Greco S, Elia MG, Storelli C, Marsigliante SPKC. z require for angiotensin II- induced activation of ERK and synthesis of c-fos in MCF-7 cells. J Cell Physiol 2003; 197: 61-68.
24. Mustafi R, Cerda S, Chumsangsri A, Fichera A, Bissonnette M. Protein kinase-zeta inhibits collagen I-dependent and anchorage-independent growth and enhances apoptosis of human Caco-2 cells. Mol Cancer Res 2006; 4: 683-694.

25. Kim YS, Jin SH, Lee YH, Park JD, Kim SI. Differential expression of protein kinase C subtypes during ginsenoside Rh2-induced apoptosis in SK-N-BE2 and C6Bu-1 cells. Arch Pharmacol Res 2000; 23: 518-524.

26. Reyland ME, Barzen KA, Anderson SM, Quissell DO, Matassa AA. Activation of PKC is sufficient to induce an apoptotic program in salivary gland acinar cells. Cell Death Differ 2000; 7: 1200-1209.

27. Tanaka Y, Gavrielides MV, Mitsuuchi Y, Fujii T, Kazanietz MG. Protein kinase C promotes apoptosis in LNCaP prostate cancer cells through activation of p38 MAPK and inhibition of the Akt survival pathway. J Biol Chem 2003; 278: 33753-33762.

28. Liu W, Bagaitkar J, Watabe K. Roles of AKT signal in breast cancer. Front Biosci 2007; 12 : 4011-4019.

29. Syng-Ai C, Kumari AL, Khar A. Effect of curcumin on normal and tumor cells: role of glutathione and bcl-2. Mol Cancer Ther 2004; 3: 1101-1108.

30. Trachootham D, Lu W, Ogasawara MA, Nilsa RD, Huang P. Redox regulation of cell survival. Antioxid Redox Signal 2008; 10: 1343-1374.

31. Greco S, Muscella A, Elia MG, Salvatore P, Storelli C, Marsigliante S. Activation of angiotensin II type I receptor promotes protein kinase C translocation and cell proliferation in human cultured breast epithelial cells. J Endocrinol 2002; 174: 205-214.

32. Marsigliante $\mathrm{S}$, Vetrugno $\mathrm{C}$, Muscella $\mathrm{A}$. CCL20 induces migration and proliferation on breast epithelial cells. J Cell Physiol 2013; 228: 1873-1883.

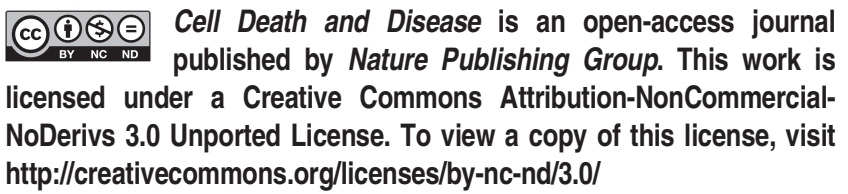

